\title{
Motrivivencia
}

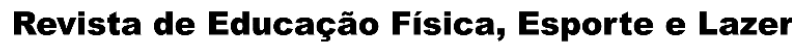

LaboMídia

\section{A (des)seriação da Educação Física no ensino médio do CAp/UFRGS: um relato de experiência do estágio de docência}

\section{RESUMO}

Este artigo apresenta algumas reflexões que emergiram de uma experiência no Estágio de Docência de Educação Física no Ensino Médio, ocorrido no CAp/UFRGS, a partir de um currículo (des)seriado. Assim sendo, mediante uma docência compartilhada, o trabalho desenvolvido sustentou-se nas práticas corporais de aventura, tendo em vista que foi uma das "modalidades" eleitas na assembleia representativa da dinâmica curricular da Educação Física na instituição quanto à definição dos conteúdos a serem trabalhados. Desse modo, tendo como escopo, neste artigo, os processos de ensino e aprendizagens na Educação Física partindo do que foi produzido sob a égide da respectiva (des)seriação, apresentamos a particularidade de sua dinâmica na Educação Física, remontando seu processo de formulação e substantivação na instituição para expor o trabalho desenvolvido no referido Estágio. Assim sendo, sustentamos as reflexões e interpretações postas, no estudo que embasa o currículo em questão bem como nas contribuições de Paulo Freire.

PALAVRAS-CHAVE: Educação física escolar; Ensino médio; Currículo; Práticas corporais de aventura

\section{Gabriel Ziel Boldori}

Licenciatura em Educação Física Universidade Federal do Rio Grande do Sul (UFRGS), Escola de Educação Física,

Fisioterapia e Dança (ESEFID), Porto Alegre, Brasil

gabrielzielboldori@gmail.com https://orcid.org/0000-0002-6746-4366

Dienifer de Lima de Oliveira

Licenciatura em Educação Física Universidade Federal do Rio Grande do Sul (UFRGS), Escola de Educação Física,

Fisioterapia e Dança (ESEFID), Porto

Alegre, Brasil dieniferzutra@gmail.com

https://orcid.org/0000-0003-0447-5778

Ivan Livindo de Senna Corrêa

Doutorado em Educação

Universidade Federal do Rio Grande do

Sul (UFRGS), Porto Alegre, Brasil

ivanlivindo@gmail.com

는 https://orcid.org/0000-0003-0186-6511

Denise Grosso da Fonseca

Doutorado em Educação

Universidade Federal do Rio Grande do

Sul (UFRGS), Porto Alegre, Brasil

dgf.ez@terra.com.br

https://orcid.org/0000-0001-6206-4729 


\title{
The (un)serialization of Physical Education in CAp/UFRGS secundary education: an experience report from the teaching internship
}

\begin{abstract}
This article presents some reflections that emerged from an experience in the Physical Education Teaching Internship in Secondary Education, which occured at CAp/UFRGS from a (un)serialized curriculum. Therefore, through shared teaching, the work developed was sustained in the bodily practices of adventure, considering that it was one of the "modalities" chosen in the representative assembly of the curricular dynamics of Physical Education in the institution to define the contents to be worked on. Thus, having as scope in this article the teaching and learning processes in Physical Education starting from what was produced under the aegis of the respective (un)serialization, we present the particularity of its dynamics in Physical Education, going back to its process of formulation and substantiation in the institution to present the work developed in the respective Internship. Thus, we support the reflections and interpretations presented here in the study that supports the respective curriculum as well as in the contributions of Paulo Freire.
\end{abstract}

KEYWORDS: School physical education; Secondary education; Curriculum; Adventure bodily practices

\section{La (de)serialización de la Educación Física en la educación secundaria CAp/UFRGS: un relato de experiencia de la pasantía de enseñanza}

\section{RESUMEN}

Este artículo presenta algunas reflexiones surgidas de una experiencia en la Pasantía de Enseñanza en Educación Física en la Educación Secundaria, que se llevó a cabo en CAp / UFRGS a partir de un currículo (de)serializado. Así, a través de la enseñanza compartida, el trabajo desarrollado se sustenta en las prácticas corporales de aventura, considerando que fue una de las "modalidades" elegidas en la asamblea representativa de las dinámicas curriculares de la Educación Física en la institución para definir los contenidos a trabajar. Así, teniendo como alcance en este artículo los procesos de enseñanza y aprendizaje en Educación Física a partir de lo producido al amparo de la (de)serialización respectiva, presentamos la particularidad de su dinámica en Educación Física, remontándonos a su proceso de formulación y fundamentación en el Institución para presentar el trabajo desarrollado en la respectiva etapa curricular. Así, apoyamos las reflexiones e interpretaciones aquí presentadas en el estudio que sustenta el respectivo currículum, así como en los aportes de Paulo Freire

PALABRAS-CLAVE: Educación física escolar; Educación secundaria; Curriculum; Prácticas corporales de aventura 


\section{INTRODUÇÃO}

Este Relato de Experiência emerge de reflexões produzidas ao longo do Estágio de Docência de Educação Física no Ensino Médio, realizado no Colégio de Aplicação da Universidade Federal do Rio Grande do Sul (CAp/UFRGS), no segundo semestre do ano de 2019. A construção do Estágio deu-se em duplas, sendo a docência compartilhada desde o planejamento até a concretude do trabalho desenvolvido na Instituição. Desse modo, muitas foram as apreensões no decurso de nossa experiência, pautando reflexões em diálogos junto a outros estagiários que, assim como nós, também experimentaram a docência nessa importante etapa do curso. Assim, compreendemos este Relato como fruto de um trabalho que foi materializado mediante, principalmente, a intencionalidade de um processo orientado pela ação-reflexão (FREIRE, 2005).

Considerando a abrangência de nossa experiência no Estágio, cujo percurso possibilitou a produção de conhecimentos didático-pedagógicos junto aos professores de Educação Física da Instituição, buscamos delimitar este Relato reflexivo à temática do processo de ensino e aprendizagens a partir de uma proposta curricular (des)seriada, visto ser essa a organização proposta pelo Colégio para a Educação Física no Ensino Médio Regular. Sendo assim, no nosso entendimento, tal proposição apresenta uma forma alternativa de organizar o currículo, buscando outras possibilidades para o desenvolvimento dos processos de ensino e aprendizagens na Educação Física escolar, como a que apresentaremos.

Em síntese, a forma de organizar a (des)seriação passa por uma assembleia com a participação de estudantes do $1^{\circ}, 2^{\circ}$ e $3^{\circ}$ anos do Ensino Médio Regular e professores de Educação Física da Instituição no início de cada trimestre constitutivo do ano letivo, com vistas à eleição de modalidades $^{1}$ (práticas corporais) (LETTNIN, 2013) as quais representam os conteúdos a serem trabalhados. Como o início das atividades do estágio ocorreu concomitante com a realização da assembleia que marcou a transição para o terceiro e último trimestre letivo, pudemos participar de sua construção, sendo eleitas as seguintes modalidades: futebol, vôlei, futsal, handebol, esportes de rede e raquete, tênis de mesa e práticas corporais de aventura. Sendo que nos propusemos trabalhar esta última.

Ao final, contabilizamos18 dias de Estágio de Docência no CAp/UFRGS, sendo, desse total, 16 encontros direcionados às aulas de Educação Física e dois encontros dedicados ao planejamento

\footnotetext{
${ }^{1}$ Como mostraremos na próxima seção, o estudo de Lettnin (2013) é um marco referencial importante a este Relato, tendo em vista que a autora estudou o processo de formulação e implementação do currículo (des)seriado que tratamos neste artigo. Em seu estudo, Lettnin (2013) denomina "práticas corporais" também como "modalidades". Todavia, no Projeto Político Pedagógico (PPP) do CAp/UFRGS utiliza-se apenas a denominação "modalidades". Portanto, utilizaremos também o termo "modalidade" para nos referirmos às Práticas Corporais de Aventura assim como outras práticas corporais citadas ao longo deste Relato de Experiência.
} 
da Olimpíada do CAp/UFRGS (OCA) ${ }^{2}$. As aulas, de acordo com o currículo da Instituição, que contempla 3h/aulas semanais para a Educação Física, ocorreram nas segundas (2 períodos) e quartas-feiras (1 período), contabilizando, ao fim, 28 períodos/horas-aula mediados.

Cabe ressaltar que o trabalho desenvolvido a partir das práticas corporais de aventura, foi construído junto a um coletivo formado pelo professor de Educação Física da Instituição, e outros três professores-monitores ${ }^{3}$. Desse modo, após diálogos com a turma inscrita na modalidade a qual nos propusemos trabalhar - e que era constituída, em sua maioria, por estudantes com uma trajetória na Instituição desde o Ensino Fundamental -, pudemos definir, a partir dos conhecimentos já carregados pelos estudantes, as seguintes práticas corporais para pautar o trabalho a ser produzido: rapel, tirolesa, parkour e slackline. Todavia, tendo em vista o quantitativo docente envolvido, nossa contribuição ao trabalho desenvolvido com as práticas corporais de aventura materializou-se na organização de situações de ensino e aprendizagens com a prática corporal slackline.

Assim, à viabilidade das experiências que buscávamos propor, contemplamos no planejamentoespaços dos mais diversos, tais como a estrutura interna dos prédios constitutivos da Instituição, bem como o ambiente de seu entorno, isto é, o florestal do campus do Vale da UFRGS. Como proposta avaliativa, combinamos com a turma que se faria a produção de um vídeo, em duplas, sobre o trabalho construído ao longo do trimestre, no qual deveria conter registros (fotos, vídeos etc.) das experiências que emergiram de cada encontro. Combinamos uma data e organizamos um seminário de fechamento das atividades, onde foram apresentadas as produções pelos estudantes.

Antes de adentrarmos mais enfaticamente no trabalho realizado, gostaríamos de compartilhar duas questões que emergiram de uma reflexão coletiva proposta no primeiro encontro da turma matriculada no Estágio de Docência de Educação Física no Ensino Médio, ainda na ESEFID, acerca da realidade das diversas Redes de Ensino no que tange às condições de trabalho e às consequentes implicações na prática educativa do professorado de Educação Física: como percebemos a inserção da Educação Física no Ensino Médio hoje, e sua contribuição na construção

\footnotetext{
${ }^{2}$ A Olimpíada do Colégio de Aplicação da UFRGS (OCA) ocorre no último trimestre letivo e ao longo de uma semana, reunindo atividades no período da manhã e tarde. Esse evento, organizado pelo professorado de Educação Física, é um momento pedagógico de relevância ímpar à Instituição, uma vez que mobiliza a totalidade de estudantes em atividades culturais e esportivas (de competição ou não), bem como a realização e participação de/em cursos a partir de temas de interesse da comunidade.

${ }^{3}$ São licenciandos da UFRGS e bolsistas de projetos de extensão do Colégio de Aplicação. Dentre suas atribuições constam o auxílio ao professor, o qual foi o nosso supervisor, em cursos de Extensão na temática das práticas corporais de aventura, e também a monitoria nas aulas de Educação Física nessa temática. Para mais informações sobre o curso de extensão na temática das práticas corporais de aventura, acessar o link: https://www.ufrgs.br/colegiodeaplicacao/2019/07/31/curso-praticas-corporais-de-aventura-na-escola-de-formacao-paraprofessores-abre-inscricoes/. Acessado em: 31/05/2020.
} 
de conhecimentos? Quais os pressupostos justificam a Educação Física no currículo da Educação Básica Pública e, principalmente, no Ensino Médio?

Tais questionamentos foram substanciais à reflexividade conducente de nossas experiências no CAp/UFRGS, implicando na compreensão do estágio como um "inédito viável” (FREIRE, 2005). Assim, fundamentamos as reflexões e interpretações aqui compartilhadas sob o marco representado pelo estudo de Lettnin (2013) e os estudos de Paulo Freire.

Na sequência, abordaremos a proposta curricular a qual marcou o início das inquietações e reflexões, que nos levaram à partilha de nossa experiência neste Relato.

\section{ENTENDENDO A (DES)SERIAÇÃO NA EDUCAÇÃO FÍSICA ESCOLAR DO ENSINO MÉDIO NO CAP/UFRGS}

Considerando que a proposta de (des)seriação da Educação Física emerge da construção de um novo currículo no CAp/UFRGS, Lettnin (2013) nos explica que dentre os motivos que levaram o coletivo docente da Instituição à decisão de (re)pensar a forma de conceber a organização curricular do Ensino Médio (EM), estão as normativas do Programa Ensino Médio Inovador (EMI) - emitidas pelo Ministério da Educação (MEC), no ano de 2009 - o qual propunha mudanças nessa etapa da Educação Básica priorizando uma produção de conhecimentos em uma perspectiva assentada no trabalho, ciência, tecnologia e cultura, em uma experiência formativa mais abrangente.

Segundo a autora, o Programa EMI buscava incentivar alternativas curriculares que propusessem inovações pedagógicas centradas nas singularidades dos sujeitos, tendo em vista a preocupação, sobretudo, com altos índices de evasão escolar na Educação Básica (LETTNIN, 2013). Neste sentido, a autora relata que o CAp/UFRGS congregou esforços operando em um projeto inicial, implantado ao longo do ano letivo de 2009 e avaliado coletivamente pela Instituição ao término do primeiro ano de sua experimentação. Todavia, aponta que o professorado do CAp/UFRGS identificou falhas de ordem prática no empreendimento das alterações curriculares propostas, levando o coletivo a novas reflexões no ano seguinte, buscando resolvê-las.

$\mathrm{Na}$ esteira de tal pensamento,no ano de 2011 ainda foram aprovadas as Diretrizes Curriculares Nacionais para o Ensino Médio (DCNEM), fomentando o respectivo processo que naquele momento buscava a assunção de uma proposta curricular balizada, portanto, pelas normativas do Programa EMI, as novas orientações das DCNEMe, sobretudo, pelas aprendizagens a partir da experiência com a proposta anteriormente concretizada:emergindo desse processo o 
projeto curricular atual da Instituição, denominado Ensino Médio em Rede (EMR) ${ }^{4}$ (LETTNIN, 2013).

Como visto, a reestruturação curricular emergiu da necessidade de se pensar soluções à evasão escolar no Ensino Médio, propondo um processo que, conforme orientações do Programa EMI, abrangesse as experiências formativas dos educandos. No entanto, Lettnin (2013) nos mostra que, no caso da Educação Física escolar, há uma espécie de evasão particular rotineira em sua historicidade, ou seja, a evasão dos estudantes das aulas de Educação Física. A autora aponta que essa evasão ocorre, muitas vezes, pela falta de interesse dos estudantes no trabalho desenvolvido pelo respectivo componente curricular, o que no seu entendimento decorre de um ensino pautadopelo prisma da aptidão física, privilegiando os aspectos físico-motores/biodinâmicos das práticas corporais trabalhadas, o que provocaria a exclusão daqueles e daquelas "menos habilidoso(a)s e/ou aptos(a)" à realização das atividades desenvolvidas (LETTNIN, 2013).

Em vista disso, inquietações emergentes da reflexividade em torno da individualidade da maturação biológica dos estudantes (em contraposição à compreensão tácita de que o desenvolvimento biológico ocorre concomitante à idade cronológica do sujeito, subjacente à seriação curricular tradicional), igualmente da diversidade e complexidade característica das afinidades sociais do coletivo discente, levaram Lettnin (2013) à ideia de lançar mão a uma nova proposta curricular para a Educação Física no Ensino Médio do CAp/UFRGS:tomando a proposta de (des)seriação como alternativa aos prejuízos consequentes de um modelo curricular tradicional que, conforme compreende a autora, ao segregar os estudantes por faixas etárias desconsidera as individualidades e especificidades das diferentes capacidades de aprendizagem (LETTNIN, 2013). Desse modo, ela nos explica que:

Avançando os estudos e as discussões sobre esse problema, a presente pesquisa apontou a proposta de (des)seriar o EM para compor as turmas de EF tentando trazer afinidade de gosto pela prática, pelo grupo de alunos e pelo nível de conhecimento. Esta proposta está fundamentada na filosofia da diferença defendida por Foucault, Deleuze, Espinosa, Bergson e Nietzsche, que tem interesse pela diversidade, pluralidade e singularidade do ser, e também, na teoria da maturação biológica que entende que o amadurecimento do indivíduo não depende exclusivamente da idade cronológica, ocorre em ritmos e tempos diferentes. (LETTNIN, 2013, p. 83)

\footnotetext{
${ }^{4}$ Como delimitamos este Relato de Experiência na temática do processo de ensino e aprendizagens, tendo em vista a particularidade da (des)seriação da Educação Física escolar no currículo do ensino médio do CAp/UFRGS, optamos por não aprofundarmos a totalidade da dinâmica curricular da Instituição. Para tal, sugerimos a leitura da Tese de doutorado de Lettnin (2013), assim como uma consulta ao site do CAp/UFRGS, uma vez que, nele, constam informações sobre os projetos de ensino de todas as etapas constitutivas da Educação Básica, o qual pode ser acessado através do link: https://www.ufrgs.br/colegiodeaplicacao/ensino/projetos-de-ensino/. Acessado em: 22/03/2019
} 
Pensando a diversidade, pluralidade e singularidade do "ser", a autora compreende que a proposta de (des)seriação viabiliza processos de ensino e aprendizagens mais saudáveis no sentido de proporcionar aos estudantes a oportunidade de adequar os processos às suas possibilidades, favorecendo um ambiente de aprendizagem com vistas a "[...] um estilo de vida cada vez mais saudável fisicamente, socialmente, psicologicamente e espiritualmente.” (LETTNIN, 2013, p. 83). Neste sentido, a pesquisadora compreende a Educação Física escolar como "[...] uma área que trata da cultura corporal de movimento e que tem como finalidade introduzir e integrar o aluno nessa esfera, formando o cidadão que vai produzi-la, reproduzi-la e também transformá-la” (Ibidem, p. 83), entendendo também que seus objetivos vão além da saúde física (Ibidem, p. 42, 2013). Assim, a autora defende que a (des)seriação proposta mediante a (re)organização das turmas e a eleição de modalidades (práticas corporais) em um sistema de votação por grupos de estudantes, favoreceria uma aproximação por afinidades sociais, níveis de desenvolvimento e capacidades de aprendizagem -ou seja, na contramão do desinteresse aqui já comentado - de forma que valorizasse um processo centrado nas singularidades e interesses dos estudantes (LETTNIN, 2013).

Sendo assim, já na vigência do projeto EMR, as aulas de Educação Física foram reposicionadas no período da tarde juntamente com as disciplinas de caráter eletivo (disciplinas eletivas - DE) e o projeto de iniciação científica (IC), ou seja, no contra-turno escolar. Desse modo, ficou acordado que, da totalidade de estudantes matriculados no ensino médio (em torno de 210), uma metade seria direcionada às atividades das DE e do projeto de IC, sendo a outra metade de estudantes às atividades da Educação Física.

Atualmente, nas atividades referentes à Educação Física escolar, atendendo à (des)seriação, é feita uma divisão das turmas em dois grandes grupos: o das turmas ímpares $(101,201,301)$ e pares $(102,202,302)$, haja vista o processo de eleição das modalidades. Assim, mediante duas assembleias relativas aos respectivos grupos, com a participação dos professores de Educação Física e os estudantes, são escolhidas as modalidades e posteriormente constituídas as turmas.

Desse modo, a (des)seriação representativa da proposta de Lettnin (2013) passa trimestralmente por um processo construído de forma coletiva mediante, primeiro, a apresentação de propostas tanto por estudantes como pelos professores,seguindo por diálogos e reflexões visando a apreensão de suas possibilidades e, por fim, com base no sistema de votação simples, chegando à definição de 10 (dez) modalidades, sendo cinco para as turmas pares e cinco para as turmas ímpares, as quais comporão as turmas de estudantes das três séries do Ensino Médio.

Como expresso na seção introdutória deste Relato de Experiência, o início das atividades do Estágio ocorreu concomitante com a realização das assembleias. Portanto, tivemos a oportunidade de experienciar esse processo em sua totalidade, conhecendo os estudantes e sugerindo propostas de 
trabalho a partir de algumas modalidades de nosso interesse. Em vista disso, compreendemos que esse momento foi fundamental à forma como concebíamos a construção do planejamento, assunto que iremos apresentar/debater na próxima seção.

\section{DA (DES)SERIAÇÃO À CONSTRUÇÃO DO PLANEJAMENTO}

Nossa decisão ${ }^{5}$ pelas práticas corporais de aventura, modalidade eleita na assembleia construída pelas turmas pares, passou pela apreensão de dois elementos: o primeiro deles foi a sua historicidade na Instituição; o segundo, a experiência do professor que viria a ser o titular da modalidade naquele momento. Ou seja, sabíamos que as práticas corporais de aventura constituíam a cultura do CAp/UFRGS, visto que compunha temática de cursos de extensão, bem como é, repetidas vezes, eleita como conteúdo a ser trabalhado nas aulas de Educação Física. Em vista disso, pensamos que o trabalho com tal modalidade proporcionaria a construção de experiências/aprendizagens pertinentes à visualização de possibilidades de ensino na Educação Física escolar a partir dessa temática.

Assim sendo, o planejamento começou a tomar forma no primeiro encontro com a turma, ocorrido na segunda semana do mês de setembro de 2019. Combinamos com o professor titular/supervisor que reservaríamos os dois primeiros encontros com os estudantes para conhecê-los e, na medida do possível, buscaríamos compreender como o trabalho na perspectiva da (des)seriação era concebido pela turma, bem como os significados compartilhados a respeito das práticas corporais de aventura. Desse modo, no primeiro dia de aula, após nos apresentarmos aos estudantes, buscamos ouvir um pouco de suas histórias pela Instituição - retomando, principalmente, suas experiências na Educação Física em trimestres anteriores -, momento o qual além de também apresentarem-se, organizamos coletivamente como ocorreriam os encontros, considerando o quantitativo de professores envolvidos.

A partir dos relatos dos estudantes e dos diálogos iniciais, foi possível identificar que muitos dos que haviam realizado a matrícula na modalidade já carregavam experiências com práticas corporais de aventura, e o que parecia comum em suas narrativas naquele momento, sobretudo no que se refere à escolha pela modalidade, era a compreensão acerca de sua "pouca" exigência física.

Relevância aos aspectos físicos das práticas corporais de aventura que nos leva à reflexividade a respeito da disputa epistemológica pautada historicamente no âmbito do currículo da

\footnotetext{
${ }^{5}$ A dinâmica da escolha das modalidades, por parte dos estagiários, ocorre da seguinte forma: após a eleição das modalidades em assembleia, as duplas de estagiários escolhem a modalidade com a qual construirão suas experiências no Estágio.
} 
Educação Física escolar, e neste mesmo sentido, à visualização da lógica excludente do paradigma da aptidão física.Por outro lado, em recente estudo (CORRÊA; GONÇALVES, 2016) realizado na mesma Instituição, o qual buscou investigar as perspectivas dos estudantes que participaram da modalidade a qual pauta este texto, no ano de 2015, interpreta que a não exigência de treinamento prévio à experimentação das práticas corporais de aventura é um dos motivos que influencia a escolha por esta modalidade, levando a uma maior participação dos estudantes nas atividades realizadas (CORRÊA; GONÇALVES, 2016).

Em vista disso, entendemos que, apesar da intencionalidade que permeia a (des)seriação do currículo da Educação Física instigar o reposicionamento dos processos de ensino e aprendizagens em favor das culturas e condições de aprendizagem dos estudantes (LETTNIN, 2013), os significados compartilhados pela turma, assim como os achados no estudo de Corrêa e Gonçalves (2016), talvez apontem a necessidade de um melhor esclarecimento por parte do professorado de Educação Física da Instituição a respeito do compromisso assumido na proposta de (des)seriação curricular; sobretudo, na problematização junto aos estudantes em torno as práticas corporais eleitas em assembleia.

Assim, aproveitamos as narrativas dos estudantes e propusemos à turma a reflexividade acerca das valências físicas citadas, buscando relacioná-las com outras práticas corporais e as justificativas compartilhadas no que diz respeito ao interesse pela modalidade. Desse modo, problematizamos, naquele momento: há quem não possa conhecer e/ou experimentar as práticas corporais de aventura? há como pensarmos os aspectos físicos inerentes às suas práticas de forma não excludente? A partir das respostas dos estudantes, fomos definindo a especificidade do trabalho naquele trimestre, o qual se assentou no aprimoramento de técnicas específicas de conhecimento dos estudantes, bem como na produção de experiências com novas práticas corporais.

Dessa forma, a metodologia de ensino foi sendo estabelecida a partir da dialogicidade empreendida com os sujeitos naquele espaço-tempo, considerando a dinamicidade de suas experiências com a temática trabalhada, a viabilidade material da instituição e a especificidade do número de docentes envolvidos no trabalho com a respectiva modalidade. É neste sentido que compreendemos a substantividade da contextualização da experiência didática na Educação Física escolar, ou seja, a composição com o outro e, portanto, a intencionalidade de um currículo reposicionado em favor das culturas e capacidades de aprendizagem dos estudantes, isto é, de suas singularidades, conforme propõe a (des)seriação da Educação Física escolar no ensino médio do Cap/UFRGS (LETTNIN, 2013).

A respeito das práticas corporais definidas para comporem o trabalho com a temática proposta, foram elencadas: rapel, tirolesa, parkour e slackline. A partir disso, foram organizados 
grupos de trabalho com os seguintes objetivos gerais: a) Valorizar a diversidade de práticas corporais, reconhecendo-as como produtos sócio-históricos; b) Reconhecer e respeitar a pluralidade de manifestações/expressões culturais/corporais; c) Valer-se da coletividade para a construção de conhecimentos; d) Valer-se das situações de ensino organizadas enquanto plataformas à leitura de mundo; e) Compreender os conhecimentos/saberes produzidos nos encontros enquanto produção cultural humana.

Considerando o trabalho em grupos e os objetivos gerais mencionados, definimos alguns procedimentos comuns para construirmos diálogos entre as situações de aprendizagem, sendo eles: a) A consideração dos conhecimentos dos estudantes no planejamento das atividades; b) A definição de espaços comuns à organização das situações de ensino e aprendizagens; c) A produção de uma avaliação conjunta. Tendo em vista que ficamos responsáveis pelo trato com a prática corporal slackline, foram elencados, como objetivos específicos: a) Identificar e compreender elementos que justificam a inclusão da prática corporal slackline na categoria práticas corporais de aventura; b) Experimentar a prática corporal slackline em diferentes ambientes e seus diferentes tipos (slackline, highline e trickline); c) Tomar conhecimento do equipamento básico, compreendendo suas diferentes disposições, assim como as diferenças de sua experimentação em espaços diversos; d) Identificar os aspectos envolvidos na prática corporal que permitem o avanço na prática experimentada; e) Reconhecer elementos de outras práticas corporais na experimentação do slackline; f) Visualizar possibilidades de ajuda do colega na experimentação da prática slackline;

g) Compreender a contribuição de diferentes técnicas à experimentação da prática corporal slackline;

Entendemos que a construção do planejamento junto aos estudantes produziu condições favoráveis à coletividade nas sociabilidades mediadas no respectivo processo didático, tensionando significações consubstanciadas por epistemologias conservadoras de práticas de ensino, na contramão de uma cultura de silêncio dos estudantes (FREIRE, 2005). Neste sentido, compreendemos que a materialização de um currículo pensado a partir da necessidade do olhar aos sujeitos requer, sobretudo, a assunção de condições em que a escuta e o diálogo representem pilares estruturantes do trabalho a ser desenvolvido. Desse modo, entendemos que a substantivação de experiências mais humanizadas só será realizada no comprometimento mútuo dos sujeitos com a experiência proposta - isto é, porque humanizada, na intersubjetividade coletiva do processo. Permitindo-nos estender tal reflexão, pensemos juntos: em um trabalho estabelecido a priori da apreensão das experiências, bem como dos significados compartilhados pelos estudantes referentes à escolha pela modalidade, o que estaríamos aprendendo? A partir de que contexto partiriam as 
aprendizagens? Quais sentidos teriam as práticas corporais definidas enquanto objetos de conhecimento?

$\mathrm{Na}$ estruturação do planejamento, idealizamos 20 encontros ao longo do trimestre. Entretanto, desde o início das atividades, ainda na ESEFID, já prevíamos que talvez o cronograma do Estágio de Docência no Ensino Médio, bem como o calendário do CAp/UFRGS viessem a sofrer modificações, tendo em vista as diversas manifestações organizadas contra os ataques às Instituições Federais de Ensino (IFE), empreendidos pelo MEC $^{6}$. Assim, contabilizamos ao total 16 encontros, permitindo-nos tempo hábil à substantividade do planejamento definido e, sobretudo, à produção de experiências.

Portanto, na sequência, apresentaremos o trabalho produzido a partir da prática corporal slackline, com a qual planejamos situações de ensino e aprendizagens que marcaram nossa contribuição ao trabalho no Estágio de Docência de Educação Física no Ensino Médio.

\section{DO PlaneJAMENTO VIÁVEL À CONTRIBUiÇÃO AO TRABALHO A PARTIR DA PRÁTICA CORPORAL SLACKLINE}

A partir das reflexões produzidas junto aos estudantes, fomos compondo o emaranhado de possibilidades e sistematizando o planejamento viável ao respectivo trimestre. Desse modo, foram formados três grupos ${ }^{7}$ para que pudéssemos organizar nossos encontros, acordo que perdurou até o fim do trimestre.

Considerando ainda os significados compartilhados pela turma, entendemos que o trabalho com a prática corporal slackline deveria comportar diferentes ritmos em relação às outras atividades concomitantemente realizadas, não apenas no que tange à particularidade de sua prática, mas pelo fato de que ainda deveríamos nos aproximar dos sujeitos com os quais trabalharíamos, exigindo-nos os acordos didáticos necessários a fim de que nos "encharcássemos" de suas culturas (FREIRE, 1985), representações e conhecimentos, favorecendo, portanto, um processo de ensino e aprendizagens de forma dialógica e reflexiva, ou seja,ao encontro das singularidades dos sujeitos.

Em vista disso, considerando os objetivos gerais estabelecidos, em nosso primeiro encontro, já na condição de mediadores do processo a ser construído, buscamos problematizar tal modalidade

\footnotetext{
${ }^{6}$ Inclusive, o primeiro encontro do Estágio, marcado para a primeira quarta feira da segunda semana do mês de Agosto do ano de 2019, foi remarcado para o dia 14/08, tendo em vista a adesão, primeiro, dos técnicos administrativos e, posteriormente, dos professores, professoras e estudantes da UFRGS, à greve nacional pela Educação, organizada na terça feira do dia 13/08 e convocada pelo Sindicato dos Técnicos Administrativos da UFRGS, UFCSPA e IFRS (ASSUFRGS): manifestação contra a contraditória reforma da Previdência e o projeto neoliberal/neoconservador de privatização das Universidades e Institutos Federais de Educação (IFE’s).

$7 \mathrm{O}$ trabalho por grupos viabilizou a organização das atividades, dividindo os docentes envolvidos e as práticas corporais definidas nos respectivos grupos.
} 
a partir das condições físico-motoras-culturais dos estudantes, tendo em vista que o "equilíbrio" foi uma característica ressaltada pelo coletivo em nossos diálogos iniciais. Neste sentido, partindo de algumas atividades em duplas, as quais buscaram produzir condições de (des)equilíbrio corporal, procuramos discutir como as diferentes experiências com práticas corporais influenciavam na construção de suas valências físicas, problematizando os aspectos contextuais, temporais e culturais das práticas corporais "marcadas" em suas trajetórias formativas, buscando, ainda, relacionar essas experiências com as representações atribuídas às práticas corporais de aventura. Desse modo, a partir das experiências retomadas narrativamente naquele momento, também fomos identificando elementos dessas experiências que pudessem agregar às experimentações das práticas corporais que vivenciávamos naquele trimestre, orientando nossas próximas aproximações.

Assim, fomos traçando o caminho - ou, metaforicamente, "percorrendo a fita" - a partir das relações estabelecidas com o coletivo e as construções emergentes dos encontros. Tendo em vista a exploração e problematização das trajetórias culturais em nosso primeiro encontro, partimos, na sequência, sobre como o olhar do colega ${ }^{8}$ e suas vivências poderiam contribuir à experimentação da prática corporal trabalhada. Desse modo, propusemos aos estudantes que buscassem identificar, a partir do diálogo e orientações de/com diferentes colegas, elementos que ajudassem à apropriação da prática corporal, instigando o compartilhamento de experiências acerca da temática trabalhada, dando forma, assim, à coletividade e contribuindo para uma "visão da totalidade" (FREIRE, 1981) no que tange às convergências e singularidades das experiências compartilhadas. Neste aspecto, foram emergindo as primeiras técnicas necessárias à sistematização da prática do slackline, tal como a técnica de subida na fita e o auxílio da falsa baiana9 .

Entendemos que a experiência possibilitada pelo desafio didático proveniente da proposta curricular (des)seriada provocou-nos, além da ressignificação do processo de ensino e aprendizagens da Educação Física escolar, a compreensão de que a formação de professores no chão da escola constitui-se, principalmente, da rigorosidade a que nos permitimos escutar o outro na complexidade de sua formação como sujeito. Neste sentido, compreendemos que tal compromisso nos proporcionou o entendimento sobre a importância de se produzir processos de ensino e aprendizagens fundados por experiências mais humanizadas, reafirmando, desse modo, a urgência de práticas educativas na Educação Física escolar que se (re)façam em favor das culturas corporais de movimento dos estudantes (BOSSLE, 2018).

\footnotetext{
${ }^{8}$ Compreendemos que a integração propositiva dos estudantes, mediante a dinâmica curricular (des)seriada, não decorre por si só quando ausente a intencionalidade de um trabalho que venha a reforçar sociabilidades coletivas.

${ }_{9}^{9}$ Aqui cabe ressaltar que os estudantes, ao transitarem entre as situações de ensino organizadas, foram intercambiando suas apreensões, o que ficou evidente na emergência de possibilidades de sistematização da prática do slackline, também contribuindo, em se tratando desse intercâmbio, à percepção da totalidade (FREIRE, 1981) do processo de ensino e aprendizagens.
} 
Dos vários atravessamentos no processo experiencia do, o desafio de pensar uma avaliação que contemplasse a dinamicidade do trabalho construído é o que trataremos a seguir.

\section{DA DINAMICIDADE DAS EXPERIÊNCIAS À CONSTRUÇÃO DA AVALI(AÇÃO) COMO EXERCÍCIO DE (RE)LEITURA A PARTIR DA DIVERSIDADE DE SENTIDOS}

Conforme fomos produzindo vivências a partir das práticas corporais com as quais trabalhamos, o plano de trabalho foi sendo materializado e a avaliação tomando forma ao encontro de uma proposta convergente com a dinamicidade das experiências produzidas. Esse momento foi pertinente ao intercâmbio de conhecimentos entre os professores envolvidos, considerando a encruzilhada de concepções pedagógicas e experiências na docência, materializando a via de mão dupla representada pelos estágios curriculares no que se refere à viabilidade do compartilhamento e produção de conhecimentos entre as instituições de ensino.

Assim, após algumas leituras e discussões sobre a temática da avaliação na Educação Física escolar (TAVARES; FONSECA, 2016; FONSECA, 2015; CORREAA; MORO, 2004; entre outros) e, principalmente, a reflexividade sobre dos significados compartilhados pelos estudantes ao longo do percurso, definimos que usaríamos instrumentos/dispositivos audiovisuais - quais sejam, celulares, câmeras fotográficas, etc. - como recursos à avaliação ${ }^{10}$.

Desse modo, combinamos com a turma a realização de um trabalho de fechamento do trimestre, que consistiria na produção de um vídeo síntese constituído de registros realizados ao longo de nossos encontros. Assim, pensamos que a utilização de tais instrumentos poderia servir como mediações alternativas ao longo da experiência, de modo que os estudantes pudessem registrar suas vivências a partir de suas próprias "lentes" e, dessa forma, produzindo condições para que pudéssemos visualizar e problematizar a diversidade do que poderia emergir dos respectivos registros.

Representando, portanto, uma plataforma à (re)leitura dos significados (re)produzidos e (com)partilhados ao longo do processo (CORREAA; GONÇALVES, 2016), os registros serviram como codificações à reflexividade individual e coletiva, ao encontro de um processo orientado pela diversidade, pluralidade e singularidade dos sujeitos, tal como propõe Lettnin (2013).

\footnotetext{
${ }^{10}$ Decisão que também passou pelo conhecimento sobre as condições de acesso dos estudantes aos referidos recursos. Cabe salientar que o CAp/UFRGS é uma Instituição Pública na qual o ingresso é definido por sorteio. Neste sentido, como a instituição está localizada na divisa com o município de Viamão, em uma região periférica do município de Porto Alegre, muitos dos estudantes do colégio residem em bairros localizados no seu entorno, os quais, porque desassistidos pelo poder público do município, apresentam-se em situação de vulnerabilidade social - como os bairros Agronomia e Lomba do Pinheiro.
} 
Conforme fomos nos aproximando das práticas corporais trabalhadas, estabelecemos critérios à construção dos vídeos, cujos acordos foram: a) No máximo 5 (cinco) minutos de duração; b) Construção do vídeo em duplas; c) Dados de identificação com o nome da escola, nome da modalidade trabalhada no trimestre, nome dos professores(a) e nome das práticas corporais vivenciadas; d) Breve texto/áudio/áudio-vídeo explicativo da atividade; e) Equipamentos utilizados; f) Espaços onde ocorreram os encontros; g) Fotos/vídeos dos momentos de aprendizagens; h) Breves textos/áudio das aprendizagens construídas; i) Nome das pessoas envolvidas nas práticas e descrição detalhada do processo de construção do vídeo, especificando a contribuição de cada estudante envolvido. As apresentações dos trabalhos ocorreram em nosso último encontro com a turma, ocorrido na última quarta-feira do mês de novembro de 2019.

As sínteses produzidas pelos estudantes apresentaram conteúdos diversos, emergindo convergências e singularidades no que diz respeito aos significados (com)partilhados. Observamos que os estudantes não tiveram dificuldades no trato com os instrumentos definidos, o que nos remete, principalmente, à proposta curricular da Instituição e o incentivo ao uso de tecnologias por diferentes componentes curriculares que a constituem, conforme relatado pelos estudantes ${ }^{11}$.

Neste sentido, identificamos aproximações com a perspectiva interdisciplinar interpretada por Corrêa e Gonçalves (2016) em estudo construído ${ }^{12}$ com estudantes do CAp/UFRGS, no qual foi realizado um trabalho avaliativo semelhante ao que desenvolvemos. Contudo, a proximidade a que referimos diz respeito ao que interpretamos ser uma compreensão transdisciplinar, por parte dos estudantes, das práticas corporais trabalhadas e compartilhadas nas representações projetadas em vídeo. Isso ficou evidente nas relações estabelecidas com diversos trabalhos produzidos junto a outros componentes curriculares, tais como Artes, Língua Portuguesa, Teatro e Música. Relações estas que materializadas nas diferentes técnicas fotográficas utilizadas e justificadas na busca pela sinergia entre a captação dos movimentos dos sujeitos e os respectivos ambientes nos quais eram produzidos, nas formas de apresentação das aprendizagens no que se refere à escolha por histórias narradas, descritas em texto ou, ainda, a decisão pela produção de esquetes, remontando, de forma dramatúrgica, os momentos de aprendizagens, nas também justificadas relações sinérgicas entre as

\footnotetext{
${ }^{11}$ No mesmo trimestre em que realizaram o trabalho conosco, os estudantes do $3^{\circ}$ ano matriculados na modalidade tiveram que produzir curtas-metragens para a disciplina Língua Portuguesa e Literatura. A apresentação desses trabalhos ocorreu no início do mês de novembro no Salão de Atos da UFRGS, em evento organizado pelo professor responsável. Mais informações podem ser acessadas através do link: https://www.ufrgs.br/colegiodeaplicacao/2019/11/01/iv-mostra-de-curtas-metragens-do-3o-ano-do-ensino-medio-do-ca p-ufrgs/. Acessado em: 21/07/2020.

${ }^{12}$ Os autores observaram relações e contextualizações dos conhecimentos compartilhados em vídeo pelos estudantes com saberes de áreas diversas, na perspectiva da interdisciplinaridade. Como exemplo, trazem a relação observada entre o conhecimento de diferentes tipos de relevo com a Geografia; a identificação das espécies de árvores com a Biologia; e a qualidade dos materiais no que se refere às suas resistências com os conhecimentos provenientes da Física (CORREA; GONÇALVES, 2016).
} 
ações/movimentos com determinadas músicas etc. - representações as quais compreendemos estarem "molhadas" (FREIRE; FAUNDEZ, 1985) de experiências curriculares, dando forma a visões da totalidade de suas próprias experiências.

A convergência observada nos trabalhos produzidos pelos estudantes centrou no apontamento acerca da dialogicidade do processo experienciado naquele trimestre. Na maioria das sínteses apresentada foi apontado sobre a disponibilidade dos professores envolvidos na modalidade ao diálogo, também sendo enfatizado o divertimento nas vivências construídas, corroborando com Lettnin (2013) no que se refere ao entendimento sobre da necessidade de processos de ensino e aprendizagens na Educação Física escolar que produzam sentidos para os estudantes e, assim, possam superar o reducionismo deste componente curricular ao paradigma da aptidão física e aos aspectos biodinâmicos das práticas corporais.

\section{DAS TESSITURAS EXPERIENCIAIS À TENTATIVA DE SÍNTESE: CONSIDERAÇÕES FINAIS}

Tendo em vista a proposta deste Relato, entendemos que o esforço na produção de uma escrita concisa sobre o processo experiencia do remonta uma trajetória de muitas inquietações, reflexões e possibilidades, de modo que nos leva à novas interpretações sobre o que foi vivido. Neste sentido, a ideia não foi prescrever "receitas" que ditassem o que e como fazer no chão da escola, e sim instigar reflexões a partir do trabalho realizado a fim de que venhamos a nos inspirar e acreditar no que é possível de ser feito na Educação Física escolar.

Procuramos mostrar, primeiramente, a intencionalidade que sustenta a proposição curricular do CAp/UFRGS, bem como a particularidade da (des)seriação da Educação Física no ensino médio e seus procedimentos próprios referentes à definição, por meio de assembleia, dos conteúdos a serem trabalhados. Posicionamos nossas reflexões a partir do marco teórico referenciado pelo estudo de Lettnin (2013), assumindo-nos em um percurso orientado pela ação-reflexão (FREIRE, 2005).

Assim, esforçamo-nos para compartilhar, de forma concisa, o planejamento construído junto ao coletivo discente constituído, portanto, por estudantes do $1^{\circ}, 2^{\circ}$ e $3^{\circ}$ anos matriculados na modalidade práticas corporais de aventura no último trimestre letivo do ano de 2019 , tendo o slackline como prática corporal que orientou nossas experiências no Estágio.

Considerando a particularidade da proposta curricular que pautou este Relato, as reflexões compartilhadas buscaram provocar inquietações acerca de formas mais humanizadas, porque dialógicas, de conceber os processos de ensino e aprendizagens na Educação Física escolar. Neste 
sentido, entendemos que somente mediante práticas educativas que incentivem relações intersubjetivas, e não bancárias, é que teremos condições à assunção de experiências didáticas em que a pluralidade, diversidade e singularidade dos sujeitos sejam compartilhadas e, dessa forma, visibiliza as, tal como propõe o currículo da Educação Física no Ensino Médio da Instituição (LETTNIN, 2013).

Nesta perspectiva, em vista dos desafios enfrentados no percurso de nossa experiência no CAp/UFRGS, entendemos o Estágio de Docência na perspectiva de um inédito viável (FREIRE, 2005), ou seja, no qual se pode produzir condições ao desvelamento de situações-limites representadas por significações obstaculizantes à materialização de práticas educativas a partir da concretude da escola. Desse modo, consideramos que as reuniões construídas ao longo do percurso contribuíram ao tensionamento/problematização de nossas práticas educativas, desvelando significados marcados por uma racionalidade técnico-instrumental, cuja didática e metodologia de ensino emergentes de sua influência na Educação Física escolar tendem a forjar docências na perspectiva antidialógica de uma educação bancária (FREIRE, 2005).

Para finalizar, permitindo-nos a repetição, entendemos que as ações aqui compartilhadas representam um convite à (re)significação dos processos de ensino e aprendizagens da Educação Física escolar em favor de uma perspectiva mais humanizada, de modo que, a partir da coletividade, sejam produzidas condições à emergência e problematização dos objetos de conhecimento deste componente curricular a fim de que sejam produzidos sentidos para além dos significados pré-determinadas pela cultura corporal de movimento dominante - fomentando, desse modo, o exercício diário de “ajuste das lentes"que dão foco ao compromisso que assumimos na posição de professores (FREIRE, 1979), para não perdermos de vista, sobretudo, que educação é a própria vida, e não preparação para a vida (DEWEY, 1978).

\section{REFERÊNCIAS}

BOSSLE, Fabiano; BOSSLE, Cibele Biehl. "O CONHECIMENTO DE QUEM É MAIS VALIOSO?" EDUCAÇÃO FÍSICA ESCOLAR, EDUCAÇÃO CRÍTICA E PESQUISA CIENTÍFICA NO GRUPO DIMEEF/UFRGS. In: Educação Física escolar, Etnografias e Autoetnografias: A formação de intelectuais transformadores. 1 ed. Curitiba: Editora CRV. 2018.

BRACHT, Valter. Cultura Corporal, Cultura de Movimento ou Cultura Corporal de Movimento? In: SOUZA JÚNIOR, M. Educação Física escolar: Teoria e Política Curricular, Saberes Escolares e Proposta Pedagógica. Recife: EDUPE, p. 97-106, 2005. Disponível em: $\mathrm{http}$ ://reiipefe.com/wp-content/uploads/2015/12/BRACHT_Cultura-corporal-de-movimento.pdf. Acesso em: 22 set. 2020

CORRÊA, Ivan Livindo de Senna; GONÇALVES, Mariana Barbos. Práticas Corporais de Aventura na Escola: uma experiência com o Ensino Médio. In: Anais do VIII Congresso Sulbrasileiro de Ciências do Esporte: Implicações dos Novos Marcos Legais Para a Educação Física, o Esporte e o Lazer. 
CORRÊA, Ivan Livindo de Senna; MORO, Roque Luiz. Educação Física escolar: Reflexão e Ação Curricular. Rio Grande do Sul: Unijuí, 2004.

DEWEY, John. Vida e Educação. 10 Edição. São Paulo: Melhoramentos. 1978.

FREIRE, Paulo. Ação Cultural para a Liberdade e Outros Escritos. $5^{\circ}$ Edição. Rio de Janeiro: Paz e Terra. 1981.

FREIRE, Paulo. Educação e Mudança. 12 Edição. Rio de Janeiro: Paz e Terra. 1979.

FREIRE, Paulo. Pedagogia do Oprimido. 45 Edição. Rio de Janeiro: Paz e Terra.2005.

FREIRE, Paulo, FAUNDEZ, Antonio. Por Uma Pedagogia da Pergunta. $3^{\circ}$ Edição. Rio de Janeiro: Paz e Terra. Coleção Educação e Comunicação: v. 15. 1985.

FONSECA, Denise Grosso da; MACHADO, Roseli Belmonte. Educação Física: (re)visitando a didática. Porto Alegre: Sulina, 2015.

LETTNIN, Carla da Conceição. (Des)seriação da educação física no ensino médio como proposta de contribuições à saúde: visão de alunos e professores. Tese (Doutorado). Faculdade de Educação, PUCRS, Porto Alegre, 2013.

TAVARES, Natacha da Silva.; FONSECA, Denise Grosso da. A Busca Por Uma Avaliação Emancipatória no Ensino Médio: um relato de experiência. Revista Didática Sistêmica, v. 18, p. 71-87, 2016. Disponível em: https://periodicos.furg.br/redsis/article/view/7158. Acesso em: 22 set. 2020.

\section{NOTAS DE AUTOR}

\section{AGRADECIMENTOS}

Agradecemos aos alunos e alunas do CAp/UFRGS, que foram fundamentais à concretude deste trabalho.

CONTRIBUIÇÃO DE AUTORIA - Não se aplica.

FINANCIAMENTO - Não se aplica.

CONSENTIMENTO DE USO DE IMAGEM - Não se aplica.

APROVAÇÃO DE COMITÊ DE ÉTICA EM PESQUISA - Não se aplica.

\section{CONFLITO DE INTERESSES}

Informar conflitos de interesse: financeiros, pessoais, entre possíveis revisores e editores, possíveis vieses temáticos. Para mais informações:

https://www.abecbrasil.org.br/arquivos/whitepaper_CSE.pdf

\section{LICENÇA DE USO}

Os autores cedem à Motrivivência- ISSN 2175-8042 os direitos exclusivos de primeira publicação, com o trabalho simultaneamente licenciado sob a Licença Creative Commons Attribution Non-Comercial ShareAlike (CC BY-NC SA) 4.0 International. Esta licença permite que terceiros 
remixem, adaptem e criem a partir do trabalho publicado, desde que para fins não comerciais, atribuindo o devido crédito de autoria e publicação inicial neste periódico desde que adotem a mesma licença, compartilhar igual. Os autores têm autorização para assumir contratos adicionais separadamente, para distribuição não exclusiva da versão do trabalho publicada neste periódico (ex.: publicar em repositório institucional, em site pessoal, publicar uma tradução, ou como capítulo de livro), com reconhecimento de autoria e publicação inicial neste periódico, desde que para fins não comerciais e compartilhar com a mesma licença.

\section{PUBLISHER}

Universidade Federal de Santa Catarina. Programa de Pós-Graduação em Educação Física. LaboMídia - Laboratório e Observatório da Mídia Esportiva. Publicado no Portal de Periódicos UFSC. As ideias expressadas neste artigo são de responsabilidade de seus autores, não representando, necessariamente, a opinião dos editores ou da universidade.

\section{EDITORES}

Mauricio Roberto da Silva, Giovani De Lorenzi Pires, Rogério Santos Pereira.

\section{EDITOR DE SEÇÃO}

Rogério Santos Pereira.

\section{REVISÃO DO MANUSCRITO E METADADOS}

João Caetano Prates Rocha; Keli Barreto.

\section{HISTÓRICO}

Recebido em: 22 de setembro de 2020.

Aprovado em: 01 de dezembro de 2020. 